\title{
Mechanism of chlorogenic acid treatment on femoral head necrosis and its protection of osteoblasts
}

\author{
MINGJUAN ZHANG and XIANDA HU \\ Guangzhou Vocational College of Science and Technology, Guangzhou, Guangdong 510550, P.R. China
}

Received January 29, 2016; Accepted April 25, 2016

DOI: $10.3892 /$ br.2016.679

\begin{abstract}
The aim of the present study was to investigate the therapeutic effect of chlorogenic acid on hormonal femoral head necrosis and its protection of osteoblasts. The study established a femoral head necrosis model in Wistar rats using Escherichia coli endotoxin and prednisolone acetate. The rats were divided into five groups and were treated with different concentrations of chlorogenic acid (1, 10 and $20 \mathrm{mg} / \mathrm{kg}$ ). The main detected indicators were the blood rheology, bone mineral density, and the hydroxyproline and hexosamine (HOM) contents. At a cellular level, osteoblasts were cultured and treated by drug-containing serum. Subsequently, cell proliferation and the osteoblast cycle were measured using flow cytometry, and the protein expression levels of Bax and B-cell lymphoma 2 (Bcl-2) were detected using western blotting. Chlorogenic acid at a concentration of $20 \mathrm{mg} / \mathrm{kg}$ (high-dose) enhanced the bone mineral density of the femoral head and femoral neck following ischemia. Simultaneously, blood flow following the injection of prednisolone acetate was significantly improved, and the HOM contents of the high-dose chlorogenic acid group were significantly different. The results from the flow cytometry analysis indicated that chlorogenic acid can efficiently ameliorate hormone-induced necrosis. The osteoblasts were isolated and cultured. The MTT colorimetric assay showed that chlorogenic acid at different densities can increase the proliferation capabilities of osteoblasts and accelerate the transition process of $\mathrm{G}_{0} / \mathrm{G}_{1}$ phase to $\mathrm{S}$ phase, as well as enhance mitosis and the regeneration of osteoblasts. Western blotting detection indicated that chlorogenic acid may prohibit the decrease of Bcl-2 and the increase of Bax during apoptosis, thereby inhibiting osteoblast apoptosis and preventing the deterioration of femoral head necrosis. In conclusion, chlorogenic acid at the density of
\end{abstract}

Correspondence to: Mrs. Mingjuan Zhang, Guangzhou Vocational College of Science and Technology, No. 1038 Guangcong Ninth Road, Guangzhou, Guangdong 510550, P.R. China

E-mail: jinhui506602@163.com

Key words: chlorogenic acid, hormonal femoral head necrosis, osteoblast
$20 \mathrm{mg} / \mathrm{kg}$ is effective in the treatment of hormonal femoral head necrosis, which may be applicable for future treatment.

\section{Introduction}

Femoral head necrosis, also known as avascular necrosis, is caused by partial or complete ischemia of the femoral head, followed by the pathological necrosis of bone cells, bone marrow cells and fat cells (1). Current treatments focus on surgery. However, due to its significant cost, high risk, short life of joint replacement and frequent surgeries, the majority of patients cannot afford the expense and the pain associated with the treatment $(2,3)$. Therefore, it is more practical to identify a medicine that is low cost and has fewer side effects (4). Chlorogenic acid is anti-inflammatory and antibacterial, and may effectively protect osteoblasts and cure femoral head necrosis. The present study established a rat hormone model of femoral head necrosis at the cellular level, and discussed the treatment mechanism of chlorogenic acid on activating osteoblasts and decreasing apoptosis, which may be of a specific clinical significance.

\section{Materials and methods}

Materials. Neonatal Wistar rats (SPF class) were purchased from the Animal Center of Sun Yat-sen University (Guangzhou, China). Dulbecco's modified Eagle's medium (DMEM)/F12 medium and fetal bovine serum were purchased from Gibco (Thermo Fisher Scientific, Inc., Waltham, MA, USA). B-cell lymphoma 2 (Bcl-2) monoclonal mouse anti-rabbit primary antibody (cat. no. 1790-1; 1:500) and Bax monoclonal mouse anti-rabbit primary antibody (cat. no. 1119-3; 1:500) were from Sigma-Aldrich (St. Louis, MO, USA), trypsin was from Hyclone, Co. (Thermo Fisher Scientific, Inc.) and the prednisolone acetate injection was purchased from Xianju Pharmaceutical Co., Ltd. (Zhejiang, China).

The instruments used were a $\mathrm{CO}_{2}$ incubator (Forma series; Thermo Fisher Scientific, Inc.); clean benches (Suzhou Purification Plant, Suzhou, China); microplate reader (BioTek, Swindon, UK); an inverted microscope (Nikon, Tokyo, Japan); flow cytometer (FACSCalibur; BD Biosciences, San Diego, CA, USA); electrophoresis tank, protein transfer tank, electrophoresis apparatus and power (all Bio-Rad, Berkeley, CA, USA); basic electronic balance (Mettler-Toledo Ltd., Leicester, UK); and DDL-5 centrifuge (Shanghai Anting Scientific Instrument Factory, Shanghai, China). 
Establishing the rat model. A total of 60 rats were divided into 5 groups of 12 rats, as follows: A, the normal group, which was treated with saline; B, the model group, which was treated with saline; C, chlorogenic acid low-dose group, which was treated with a $1 \mathrm{mg} / \mathrm{kg}$ dose; $\mathrm{D}$, chlorogenic acid middle-dose group, which was treated with a $10 \mathrm{mg} / \mathrm{kg}$ dose; and E, chlorogenic acid high-dose group, which was treated with a $20 \mathrm{mg} / \mathrm{kg}$ dose. Following the modeling, group B was treated daily with saline for 4 weeks, and groups C-E were treated daily at the respective doses for 4 weeks.

Hemorheological measurement. Blood samples were obtained from all the rats, and the whole blood high shear value $(200 / \mathrm{sec})$, whole blood middle shear value $(30 / \mathrm{sec})$, whole blood low shear value $(3 / \mathrm{sec})$, erythrocyte sedimentation rate $(\mathrm{mm} / \mathrm{h})$, hematocrit $(1 / 1)$ and the plasma viscosity (mPa.sec) were measured according to the manufacturer's instructions.

Detection of the bone mineral density. The left lower limb femur of the rats was obtained, the muscles and fascia were removed, and the sample was maintained under a $4^{\circ} \mathrm{C}$ environment. Subsequently, the sample was placed in a dual-energy X-ray absorptiometry for the bone mineral density measurement.

Hematoxylin and eosin $(H \& E)$ pathological observation. Samples of femoral head muscle of rats were removed, fixed by $10 \%$ neutral formalin and underwent decalcification with $5 \%$ nitric acid for 5 days. The bone tissue was pricked with a pin to test zero resistance, and following this was rinsed with clean water for $24 \mathrm{~h}$. The sample was placed in a dryer for dehydration, embed with paraffin, sliced and H\&E stained to observe the cartilage bone cells under light microscopy.

Detecting the hydroxyproline (HOP) and hexosamine (HOM) contents. The rats were anesthetized with ether, and the orbital blood was removed. A modified chloramine-T method was used to detect the contents of HOP and HOM.

Preparation of drug-containing serums and culture of osteoblasts. Following modeling and treatment, the orbital blood and blood serum were removed from the rats, mixed within the same group, and frozen to study the impact of drug-containing serum on the culture of osteoblasts in vitro. A total of 5 newborn 1-day-old rats were used, their skulls were removed under sterile conditions and placed into a petri dish containing D-Hank's solution. The inner and outer membrane were carefully removed, the sutural bone tissue was cut away, and subsequently rinsed with D-Hank's solution 3 times. The tissue was placed into $5 \mathrm{ml}$ of $0.25 \%$ trypsin and agitated at $37^{\circ} \mathrm{C}$ for a 20 -min digestion. The supernatant was removed with a sterile syringe by suction, and the sample was cut into $1 \times 1-m m$ sections and transferred into flasks. Following this, $5 \mathrm{ml}$ of $0.1 \%$ type II collagenase was added and the samples were agitated under $37^{\circ} \mathrm{C}$ for digestion, and the digestive liquid was collected.

The aforementioned process was repeated once more, and the two digestive liquids were mixed, passed through a 200-mesh sieve and centrifuged at $279.5 \mathrm{x} \mathrm{g}$ for $10 \mathrm{~min}$. The lower layer was removed and washed twice with culture solution. Following this, $2 \mathrm{ml}$ DMEM culture solution containing $15 \%$ fetal bovine serum was added, and the precipitated cell clumps were percussed to disperse uniformly. Following counting, the cells were seeded in culture flasks, with each flask containing $2 \times 10^{5}$ cells $/ \mathrm{ml}$, and the flasks were placed in a $37^{\circ} \mathrm{C}$ humidified incubator with $5 \% \mathrm{CO}_{2}$ for $12 \mathrm{~h}$. Subsequently, the solution was changed to remove the non-adherent cells, once every 2 days. After the cells were seeded in a monolayer, the sample was washed three times with D-Hank's solution, and digested with $0.25 \%$ trypsin for 5 min, passaged, and the passaged osteoblast suspension was collected.

Detecting osteoblast proliferation by the MTT assay. The passaged osteoblast suspension was centrifuged at $279.5 \mathrm{x} \mathrm{g}$ for $10 \mathrm{~min}$, the supernatant was discarded and the sample was washed twice with balanced salt solution. Following counting, the cell density was adjusted to $1 \times 10^{5} / \mathrm{ml}$. The cells were seeded in a 96-well plate, diluted 1:40 in the drug-containing serum with culture medium, and $0.1 \mathrm{ml}$ was added into each well, with 3 compound wells for each group. The samples were placed in the $5 \% \mathrm{CO}_{2}$ cell incubator at $37^{\circ} \mathrm{C}$ for $48 \mathrm{~h}$, and the MTT solution was added prior to reading the colorimetric absorbance of each well, at wavelengths of 570 and $630 \mathrm{~nm}$.

Measuring the cycle changes of the osteoblasts with flow cytometry. After $48 \mathrm{~h}$, the 4 groups were digested with trypsin, and the cell concentration was adjusted to $5 \times 10^{6} / \mathrm{ml}$, fixed with $70 \%$ ethanol for $1 \mathrm{~h}$ at $4^{\circ} \mathrm{C}$, centrifuged at $279.5 \mathrm{x} \mathrm{g}$ and washed with deionized water. Following this, $1 \mathrm{ml}$ PI-containing DNA fluorescence staining solution was placed into each well, and the samples were dyed for $30 \mathrm{~min}$ at $4^{\circ} \mathrm{C}$. Subsequent to filtering, the apoptotic cells in the $G_{1}$ phase, $S$ phase and the $\mathrm{G}_{2} / \mathrm{M}$ cell numbers were measured with flow cytometry.

Measuring Bax and Bcl-2 expression levels. After $2 \mathrm{~h}$ of spinal cord injury treatment, the spinal tissue was removed with $1 \mathrm{~cm}$ around the injury center, and the sample was immediately placed at $-80^{\circ} \mathrm{C}$ for extracting the protein. The spinal tissue was homogenized, centrifuged and the supernatant was decanted. The protein content was measured using the bicinchoninic acid assay method. A $15 \%$ gel was formulated, loaded and electrophoresis occurred prior to transferring to a membrane, which was closed with skimmed milk powder, and the samples were reacted with the primary Bcl-2 antibody, secondary antibody (goat anti-mouse) and chemiluminescence was performed.

Statistical analysis. All the experiments were repeated three times, and SPSS 13.0 (SPSS, Inc., Chicago, IL, USA) was used for the Bonferroni test and one-way analysis of variance, and pairwise comparisons were made between multiple samples. $\mathrm{P}<0.05$ was considered to indicate a statistically significant difference.

\section{Results}

Bone mineral density test. Following injection with prednisolone acetate, in comparison with group A, the femoral head 
bone mineral density of the group B exhibited significant differences, as well as the femoral neck sites, indicating the success of modeling. Following treatment, the bone mineral density of the femoral head and neck increased at different degrees corresponding to the doses of chlorogenic acid (Table I).

$H \& E$ staining. The H\&E staining observations were as follows: Group A exhibited a smooth cartilage surface, no inflammatory articular cavum and no chondrocyte necrosis, while group B demonstrated necrosis and disappearance of cartilage cell, as well as cartilage depression. Instead, there were proliferations of fibrous connective tissues, a small hemorrhage around, and more red blood cells in the marrow cavity. Group E (high-dose) exhibited mild depression of the cartilage surface, certain cell degeneration and a clearly visible joint cavity. Group D (middle-dose) revealed a smooth cartilage surface, few punctate depressions, some cell necrosis and a clearly visible joint cavity. Group C (low-dose) demonstrated focal cartilage surface defect, surrounding cell necrosis, some proliferation of fibrous connective tissue and chronic inflammatory cell infiltration in the marrow cavity (Fig. 1).

HOM/HOP analysis. Following injection with the hormones, the bone structure was destroyed and absorbed, collagen catabolism increased, and the amount of HOP metabolites was also increased. The main component of bone tissue, such as mucopolysaccharides, decomposed, leading to the decrease of HOM, the main component of mucopolysaccharides. Thus, the HOM/HOP value decreased relatively (when comparing groups A and B) (Table II).

Hemorheological assessment. The hemorheological results showed that under the condition of femoral head necrosis, whole blood viscosity significantly reduced and blood viscosity improved when comparing groups D and E with group B. An increase of the erythrocyte sedimentation rate and hematocrit indicated 'strong' (plasma viscosity), and chlorogenic acid can make them weak. While the increase of blood viscosity means 'condensate' (high shear viscosity), and chlorogenic acid can dilute it (Table III).

Impact of the drug-containing serum on osteoblast proliferation. The drug-containing serum enhanced the proliferation
Table I. Impact of drugs on bone mineral density.

\begin{tabular}{lcc}
\hline Group & $\begin{array}{c}\text { Bone density of } \\
\text { femoral head position }\end{array}$ & $\begin{array}{c}\text { Femur bone mineral } \\
\text { density neck site }\end{array}$ \\
\hline A & $0.24 \pm 0.02^{\mathrm{a}-\mathrm{c}}$ & $0.16 \pm 0.01^{\mathrm{a}-\mathrm{c}}$ \\
B & $0.09 \pm 0.00$ & $0.07 \pm 0.00$ \\
C & $0.13 \pm 0.02^{\mathrm{d}}$ & $0.10 \pm 0.01$ \\
D & $0.17 \pm 0.01^{\mathrm{d}, \mathrm{e}}$ & $0.13 \pm 0.01^{\mathrm{d}}$ \\
E & $0.20 \pm 0.02^{\mathrm{a}, \mathrm{b}, \mathrm{f}}$ & $0.14 \pm 0.02^{\mathrm{a}, \mathrm{c}, \mathrm{f}}$ \\
\hline
\end{tabular}

${ }^{\mathrm{a}} \mathrm{P}<0.01$ vs. group $\mathrm{B} ;{ }^{\mathrm{b}} \mathrm{P}<0.01$ vs. group $\mathrm{C} ;{ }^{\mathrm{c}} \mathrm{P}<0.01$ vs. group $\mathrm{D}$; ${ }^{\mathrm{d}} \mathrm{P}<0.05$ vs. group $\mathrm{B} ;{ }^{e} \mathrm{P}<0.05$ vs. group $\mathrm{C} ;{ }^{\mathrm{f}} \mathrm{P}<0.05$ vs. group $\mathrm{E}$. A, normal group; B, model group; C, chlorogenic acid low-dose group (1 mg/kg); D, chlorogenic acid middle-dose group (10 mg/kg); E, chlorogenic acid high-dose group $(20 \mathrm{mg} / \mathrm{kg})$.

Table II. Impact of drugs on HOM and HOP under femoral head avascular necrosis.

\begin{tabular}{llll}
\hline Group & HOM,$\mu \mathrm{g} / \mathrm{mg}$ & $\mathrm{HOP}, \mu \mathrm{g} / \mathrm{mg}$ & $\mathrm{HOM} / \mathrm{HOP}$ \\
\hline A & $9.04 \pm 0.35^{\mathrm{a}, \mathrm{b}}$ & $51.42 \pm 2.39^{\mathrm{a}, \mathrm{c}}$ & $0.19 \pm 0.01^{\mathrm{a}, \mathrm{b}}$ \\
B & $5.34 \pm 0.61$ & $72.77 \pm 8.81$ & $0.07 \pm 0.00$ \\
C & $7.43 \pm 0.52^{\mathrm{d}}$ & $62.11 \pm 5.01$ & $0.10 \pm 0.01$ \\
D & $7.89 \pm 0.11^{\mathrm{d}}$ & $60.02 \pm 6.23^{\mathrm{d}}$ & $0.11 \pm 0.02$ \\
E & $8.43 \pm 0.55^{\mathrm{a}, \mathrm{b}}$ & $53.21 \pm 2.43^{\mathrm{a}, \mathrm{b}}$ & $0.16 \pm 0.01^{\mathrm{b}, \mathrm{d}}$
\end{tabular}

${ }^{\mathrm{a}} \mathrm{P}<0.01$ vs. group $\mathrm{B} ;{ }^{\mathrm{b}} \mathrm{P}<0.05$ vs. group $\mathrm{C}$; ${ }^{\mathrm{c}} \mathrm{P}<0.01$ vs. group $\mathrm{C}$; ${ }^{\mathrm{d}} \mathrm{P}<0.05$ vs. group $\mathrm{B}$. A, normal group; $\mathrm{B}$, model group; $\mathrm{C}$, chlorogenic acid low-dose group $(1 \mathrm{mg} / \mathrm{kg})$; D, chlorogenic acid middle-dose group (10 mg/kg); E, chlorogenic acid high-dose group (20 mg/kg); HOM, hexosamine; HOP, hydroxyproline.

of osteoblasts, and there were significant differences between groups B and C-E (Fig. 2).

Measurement of apoptosis by flow cytometry. The $\mathrm{G}_{1}$ phase cell cycle is the preparation of DNA and protein synthesis, indicating the start of the proliferation stage. The flow cytometry analysis indicated that a large number of osteoblasts

Table III. Hemorheological results of drugs on rat blood.

\begin{tabular}{lcccccc}
\hline Group & $\begin{array}{c}\text { High shear } \\
\text { viscosity, 200/sec }\end{array}$ & $\begin{array}{c}\text { Middle shear } \\
\text { viscosity, 30/sec }\end{array}$ & $\begin{array}{c}\text { Low shear } \\
\text { viscosity, 3/sec }\end{array}$ & $\begin{array}{c}\text { Hematocrit, } \\
\mathrm{mm} / \mathrm{h}\end{array}$ & $\begin{array}{c}\text { Erythrocyte } \\
\text { sedimentation, } / 1 / 1\end{array}$ & $\begin{array}{c}\text { Plasma viscosity, } \\
\mathrm{mPa} . \mathrm{sec}\end{array}$ \\
\hline A & $14.21 \pm 1.23^{\mathrm{a}, \mathrm{b}}$ & $6.47 \pm 1.08^{\mathrm{a}, \mathrm{c}}$ & $4.56 \pm 1.07^{\mathrm{a}, \mathrm{b}}$ & $1.32 \pm 0.10^{\mathrm{a}, \mathrm{b}}$ & $0.34 \pm 0.14^{\mathrm{a}, \mathrm{b}}$ & $1.38 \pm 0.08^{\mathrm{a}, \mathrm{b}}$ \\
B & $23.55 \pm 2.06$ & $9.27 \pm 1.41$ & $6.98 \pm 0.32$ & $2.78 \pm 0.55$ & $0.72 \pm 0.24$ & $2.18 \pm 1.01$ \\
C & $17.99 \pm 2.93$ & $7.64 \pm 1.72$ & $5.87 \pm 0.09$ & $2.09 \pm 0.17$ & $0.59 \pm 0.35$ & $1.81 \pm 0.56$ \\
D & $16.41 \pm 1.57^{\mathrm{d}}$ & $7.21 \pm 1.71^{\mathrm{d}}$ & $5.22 \pm 0.56^{\mathrm{d}}$ & $1.66 \pm 0.24^{\mathrm{c}, \mathrm{d}}$ & $0.48 \pm 0.18$ & $1.65 \pm 0.28^{\mathrm{c}, \mathrm{d}}$ \\
E & $15.42 \pm 1.10^{\mathrm{a}, \mathrm{c}}$ & $6.90 \pm 1.54^{\mathrm{a}}$ & $5.00 \pm 0.43^{\mathrm{a}, \mathrm{c}}$ & $1.49 \pm 0.21^{\mathrm{a}}$ & $0.39 \pm 0.08^{\mathrm{c}, \mathrm{d}}$ & $1.44 \pm 0.32^{\mathrm{a}, \mathrm{b}}$ \\
\hline
\end{tabular}

${ }^{\mathrm{a}} \mathrm{P}<0.01$ vs. group $\mathrm{B} ;{ }^{b} \mathrm{P}<0.01$ vs. group $\mathrm{C}$; ${ }^{\mathrm{c}} \mathrm{P}<0.05$ vs. group $\mathrm{C}$; ${ }^{\mathrm{d}} \mathrm{P}<0.05$ vs. group $\mathrm{B}$. A, normal group; $\mathrm{B}$, model group; $\mathrm{C}$, chlorogenic acid low-dose group (1 mg); D, chlorogenic acid middle-dose group (10 mg/kg); E, chlorogenic acid high-dose group (20 mg/kg). 

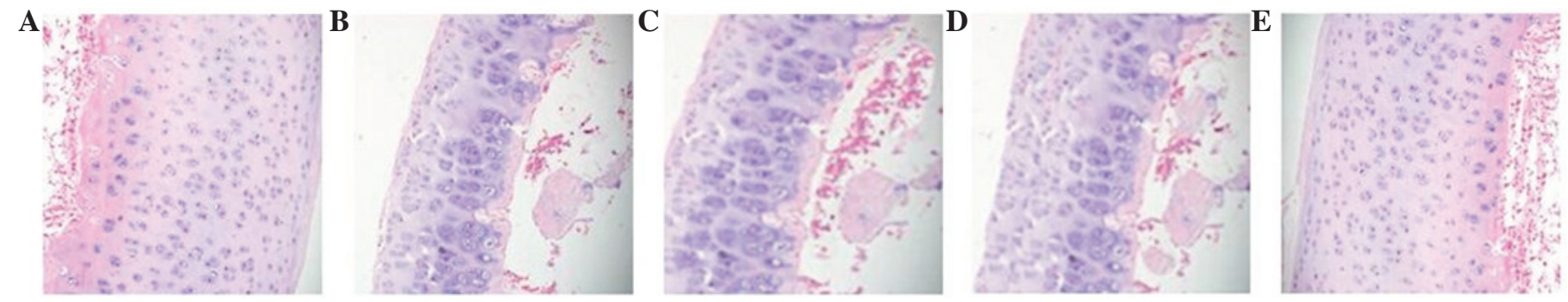

Figure 1. Hematoxylin and eosin staining of cartilage bone cells following treatment of rats with different doses of chlorogenic acid (magnification, x200). (A) Normal group; (B) model group; (C) chlorogenic acid low-dose group (1 mg/kg); (D) chlorogenic acid middle-dose group (10 mg/kg); (E) chlorogenic acid high-dose group $(20 \mathrm{mg} / \mathrm{kg})$.

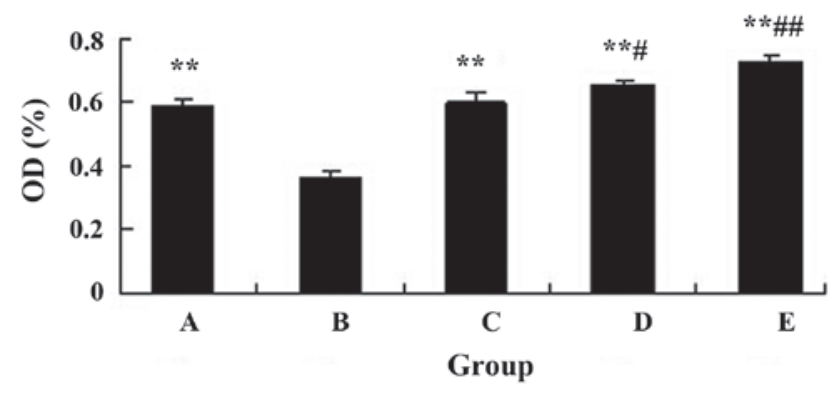

Figure 2. Impact of drug-containing serum on osteoblast proliferation following treatment with different doses of chlorogenic acid as assessed by the MTT assay. ${ }^{*} \mathrm{P}<0.05$ and ${ }^{* *} \mathrm{P}<0.01$ vs. group $\mathrm{B} ;{ }^{\#} \mathrm{P}<0.05$ and ${ }^{\# \#} \mathrm{P}<0.01$ vs. group C. A, normal group; B, model group; C, chlorogenic acid low-dose group $(1 \mathrm{mg} / \mathrm{kg}) ; \mathrm{D}$, chlorogenic acid middle-dose group $(10 \mathrm{mg} / \mathrm{kg})$; E, chlorogenic acid high-dose group $(20 \mathrm{mg} / \mathrm{kg})$.

of the group $B$ rats remained in the $G_{1}$ phase, and only a small number remained in the $\mathrm{S}$ phase, indicating that prednisolone acetate can cause numerous osteoblasts to remain in the $G_{1}$ phase, thereby blocking cells into the $S$ phase, and thus, blocking DNA synthesis, inhibiting cell mitosis and inducing apoptosis. However, following the addition of the drug-containing serum, osteoblasts in the $\mathrm{G}_{1}$ phase significantly reduced, and cells in the $\mathrm{S}$ phase increased, suggesting that the serum can facilitate osteoblast proliferation and reduce apoptosis (Fig. 3).

Measuring the expression levels of Bax and Bcl-2 using western blotting. The western blotting results showed that when compared with the normal group, the Bax expression level increased and the Bcl-2 expression level decreased. Following treatment, the Bax expression in the middle- and high-dose groups reduced significantly; however, the reduction in the low-dose group was smaller. By contrast, the Bcl-2 expression level increased significantly in the high- and middle-dose groups, and the increase was small in the low-dose group. Therefore, the treatment regulated the expression levels of these proteins, and improved the capabilities of osteoblast differentiation and maturity (Fig. 4).
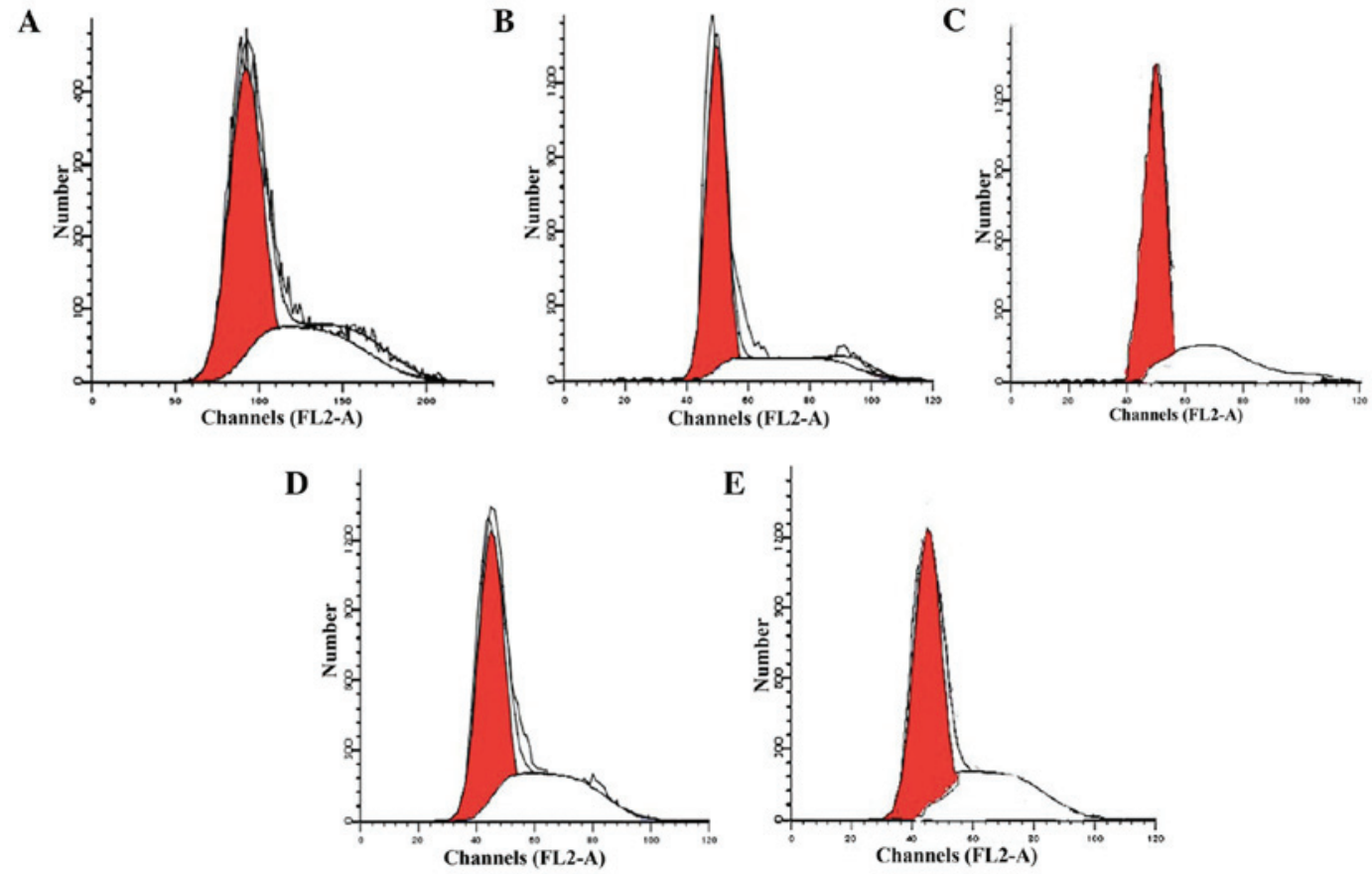

Figure 3. Effects of drug-containing serums on osteoblast cell cycle culture. (A) Normal group; (B) model group; (C) chlorogenic acid low-dose group $(1 \mathrm{mg} / \mathrm{kg})$; (D) chlorogenic acid middle-dose group (10 mg/kg); (E) chlorogenic acid high-dose group (20 mg/kg). 


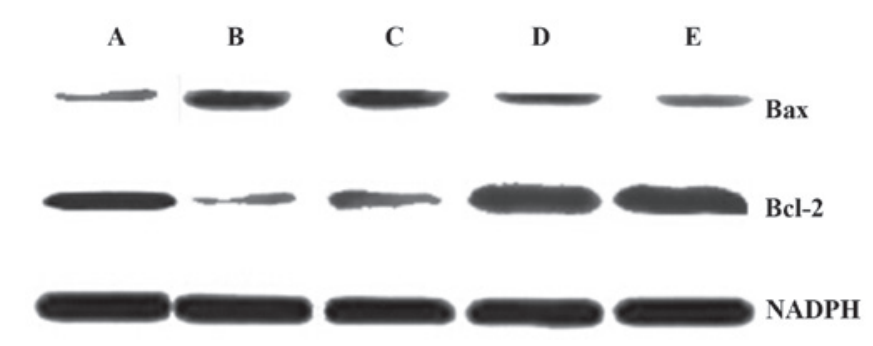

Figure 4. Impact of chlorogenic acid treatment on Bax and Bcl-2 protein expression levels. A, normal group; B, model group; C, chlorogenic acid low-dose group ( $1 \mathrm{mg} / \mathrm{kg})$; D, chlorogenic acid middle-dose group $(10 \mathrm{mg} / \mathrm{kg})$ E, chlorogenic acid high-dose group $(20 \mathrm{mg} / \mathrm{kg})$; Bcl-2, B-cell lymphoma 2 .

\section{Discussion}

Femoral head necrosis is a common orthopedic disease with one of the highest incidences of bone disease, and has high mortality and morbidity. It is known to cause significant suffering to patients $(5,6)$. Chlorogenic acid can improve cardiovascular and cerebrovascular blood flow, enhance hematopoietic and immune functions, as well as bone metabolism. The present study is based on this type of metabolism.

Osteoblasts, common in the growth of bone tissue, gather in the newly formed bone surface, and have an important role in the process of bone tissue development, bone metabolism and bone mass balance maintenance and damage repair (7-9). Femoral head necrosis is a common intractable clinical orthopedic disease, and previous studies found that it may be closely associated with the dysfunction of osteoblasts and bone marrow stromal cells (10-12). The mechanism is that bone marrow stromal cells differentiate into adipocytes, and hormones regulate bone marrow stem cell differentiation into fat cells. Following this, the stem cell pool cannot produce enough bone cells, and the adipose tissue accumulates and fills in the bone marrow cavity, thus resulting in increased internal pressure within the bone so that microvascular arterial compression occurs. Following this, venous obstruction decreases, blood stasis is blocked, metabolites accumulate, capillary permeability increases, plasma extravasation occurs and bone marrow stromal edema is observed. A vicious cycle is formulated, leading to a large incidence of osteoblast ischemic and anoxia necrosis, and avascular necrosis eventually occurs (13).

In patients with osteonecrosis, reduced viability of bone marrow stromal cells was observed in hematopoietic and interstitial tissues; proliferation was inhibited and no adequate osteoblasts were present to repair lesions in the early stage of osteonecrosis remodeling. Furthermore, in the femoral head ultrastructure necrosis, osteoblast-like cell death and lysis were also identified (14). This indicated that femoral head necrosis is closely associated with the change in the number of bone cells.

The cell MTT results suggest that chlorogenic acid of different densities can facilitate the proliferation of osteoblasts. The flow cytometry results also demonstrated that the $\mathrm{G}_{1}$ phase is the preparation stage of DNA and protein synthesis, and the marker into the proliferation phase. Numerous osteoblasts of the model group rats remained in phase $G_{1}$, and only a few remained in the $\mathrm{S}$ phase, indicating that prednisolone acetate can cause them to remain in the $\mathrm{G}_{1}$ phase, thereby blocking their entrance into the $\mathrm{S}$ phase, which inhibits DNA synthesis and cell mitosis, and thus induces apoptosis. However, following the addition of drug-containing serums, the majority of osteoblasts did not remain in the $G_{1}$ phase, but moved to the $S$ phase, indicating that the serum can enhance osteoblast proliferation and reduce apoptosis. In summary, the drug can facilitate osteoblast growth and reduce apoptosis.

The use of corticosteroid is a major factor causing avascular necrosis, and additionally, it is the most common cause of femoral head necrosis (15-17). In recent years, it can be argued that the application of hormones induced the increase of bone marrow stromal cell differentiation into fat cells and the decrease of those into the bone system, which have important roles in the pathogenesis of femoral head necrosis.

Hormone-induced cell injury is one of the important factors leading to aseptic necrosis of the femoral head, while glucocorticoids can inhibit osteoblasts growth, accelerate osteoblast differentiation and apoptosis of bone cells, accelerate the osteoclast differentiation, and induce bone marrow stromal cells transition into fat cells.

Bax and Bcl-2 are two important regulatory genes of cell apoptosis. An excess of Bax expression can accelerate apoptosis, while overexpression of $\mathrm{Bcl}-2$ can inhibit apoptosis. When the Bax/Bcl-2 ratio is greater than normal, the cells tend to undergo apoptosis, and when the ratio is smaller than normal, apoptosis is inhibited $(18,19)$. In the present study, chlorogenic acid treatment with different doses, particularly the high-dose group, can suppress the reduction of Bcl-2 and the increase of Bax in the process of osteoblast apoptosis, thereby inhibiting apoptosis and necrosis.

A previous study has shown the presence of the blood hypercoagulable state in femoral head necrosis (20), and in blood rheology, this equates to 'sticky, thick and poly tendencies', for example, an increased blood viscosity. When inflammation occurs, plasma fibrinogen components increase, and stickiness, whole blood viscosity, and erythrocyte aggregation and hematocrit all increase, leading to the hypercoagulable state of blood, and slower blood circulation. When femoral head blood perfusion is reduced, cell ischemia, anoxia and fat embolism form, intraosseous pressure increases, venous stasis and microcirculation dysfunction occurs, thus resulting in femoral head blood supply disorders, and ultimately the formation of avascular necrosis (21).

The present study also reported that chlorogenic acid of different concentrations can improve all hemorheological indicators in a varying degree, suggesting that the drug can inhibit platelet aggregation, is anti-thrombotic, lowers blood viscosity, directly affects perfusion in bone microcirculation, slows or prevents high pressure inside the bone, femoral head blood flow is smoothed, removes metabolic waste in a timely manner, relieves the state of ischemia and hypoxia, and enhances the vitality of bone cells, thereby preventing and delaying the occurrence and development of femoral head necrosis.

In conclusion, different doses of chlorogenic acid have proved therapeutically effective in the treatment of hormonal femoral head necrosis, in vivo and in vitro, protecting osteoblasts, curing necrosis and reducing apoptosis, which may be applicable for future treatment. 


\section{References}

1. Wang XS, Zhuang QY, Weng XS, Lin J, Jin J and Qian WW: Etiological and clinical analysis of osteonecrosis of the femoral head in Chinese patients. Chin Med J (Engl) 126: 290-295, 2013.

2. Zhao DW and Hu YC: Chinese experts' consensus on the diagnosis and treatment of osteonecrosis of the femoral head in adults. Orthop Surg 4: 125-130, 2012.

3. de Martel C, Ferlay J, Franceschi S, Vignat J, Bray F, Forman D and Plummer M: Global burden of cancers attributable to infections in 2008: A review and synthetic analysis. Lancet Oncol 13: 607-615, 2012.

4. Kim HA and Blanco FJ: Cell death and apoptosis in osteoarthritic cartilage. Curr Drug Targets 8: 333-345, 2007.

5. Rahman WA, Garbuz DS and Masri BA: Total hip arthroplasty in steroid-induced osteonecrosis: Early functional and radiological outcomes. Can J Surg 56: 41-46, 2013.

6. Helbig L, Simank HG, Kroeber M, Schmidmaier G, Grützner PA and Guehring T: Core decompression combined with implantation of a demineralised bone matrix for non-traumatic osteonecrosis of the femoral head. Arch Orthop Trauma Surg 132: 1095-1103, 2012.

7. Liu HY, Wu AT, Tsai CY, Chou KR, Zeng R, Wang MF, Chang WC, Hwang SM, Su CH and Deng WP: The balance between adipogenesis and osteogenesis in bone regeneration by platelet-rich plasma for age-related osteoporosis. Biomaterials 32: 6773-6780, 2011.

8. James AW, Leucht P, Levi B, Carre AL, Xu Y, Helms JA and Longaker MT: Sonic Hedgehog influences the balance of osteogenesis and adipogenesis in mouse adipose-derived stromal cells. Tissue Eng Part A 16: 2605-2616, 2010.

9. Erken HY, Ofluoglu O, Aktas M, Topal C and Yildiz M: Effect of pentoxifylline on histopathological changes in steroid-induced osteonecrosis of femoral head: Experimental study in chicken. Int Orthop 36: 1523-1528, 2012.

10. Vélez R, Hernández-Fernández A, Caminal M, Vives J, Soldado F, Fernández A, Pla A and Aguirre M: Treatment of femoral head osteonecrosis with advanced cell therapy in sheep. Arch Orthop Trauma Surg 132: 1611-1618, 2012.

11. Stuss M, Rieske P, Cegłowska A, Stêpień-Kłos W, Liberski PP, Brzeziańska E and Sewerynek E: Assessment of OPG/RANK/RANKL gene expression levels in peripheral blood mononuclear cells (PBMC) after treatment with strontium ranelate and ibandronate in patients with postmenopausal osteoporosis. J Clin Endocrinol Metab 98: E1007-E1011, 2013.
12. Kim BS, Jung JS, Jang JH, Kang KS and Kang SK: Nuclear Argonaute 2 regulates adipose tissue-derived stem cell survival through direct control of miR10b and selenoprotein N1 expression. Aging Cell 10: 277-291, 2011.

13. Youm YS, Lee SY and Lee SH: Apoptosis in the osteonecrosis of the femoral head. Clin Orthop Surg 2: 250-255, 2010.

14. Hwang Y, Park J, Choi SH and Kim G: Traumatic and Non-traumatic osteonecrosis in the femoral head of a rabbit model. Lab Anim Res 27: 127-131, 2011.

15. Takano-Murakami R, Tokunaga K, Kondo N, Ito T, Kitahara H, Ito $\mathrm{M}$ and Endo $\mathrm{N}$ : Glucocorticoid inhibits bone regeneration after osteonecrosis of the femoral head in aged female rats. Tohoku J Exp Med 217: 51-58, 2009.

16. Gangji V and Hauzeur JP: Treating osteonecrosis with autologous bone marrow cells. Skeletal Radiol 39: 209-211, 2010.

17. Seamon J, Keller T, Saleh J and Cui Q: The pathogenesis of nontraumatic osteonecrosis. Arthritis (Egypt) 2012: 601763, 2012.

18. Xie XH, Wang XL, He YX, Liu Z, Sheng H, Zhang G and Qin L: Promotion of bone repair by implantation of cryopreserved bone marrow-derived mononuclear cells in a rabbit model of steroid-associated osteonecrosis. Arthritis Rheum 64: 1562-1571, 2012.

19. Vucic D: Apoptotic pathways as targets for therapeutic intervention. Current Cancer Drug Targets 8: 86, 2008.

20. Jung HS, Kim YH and Lee JW: Duration and magnitude of extracellular signal-regulated protein kinase phosphorylation determine adipogenesis or osteogenesis in human bone marrow-derived stem cells. Yonsei Med J 52: 165-172, 2011.

21. Imhoff BR and Hansen JM: Differential redox potential profiles during adipogenesis and osteogenesis. Cell Mol Biol Lett 16: 149-161, 2011. 